\title{
The role of economic perceptions in influencing views on climate change: An experimental analysis with British respondents
}

\author{
John Kenny \\ Department of Sociology - University of Oxford, Manor Road Building, Manor Road, Oxford, \\ OX1 3UQ, United Kingdom - Email: john.kenny@ trinity.ox.ac.uk
}

The version of record of this paper has been published in Climate Policy and can be found at the following link: https://doi.org/10.1080/14693062.2017.1414026

\begin{abstract}
Existing analysis suggests that individuals may reduce their concern for and belief in climate change as a result of macro-economic difficulties. Such conclusions are predominantly based on repeated cross-sectional and pooled data making it difficult to separate out the effects of economic conditions from other explanatory factors. Approaching this question through experimentally priming individuals to feel a certain way about the economy has also proven difficult due to economic perceptions being difficult to alter in a survey setting (Kachi, Bernauer, \& Gampfer, 2015). This paper thus investigates a related question on the effect of the salience of economic perceptions on climate change views using an online question-order experiment, whereby salience denotes the prominence of the issue in the mind of the respondent. Respondents were randomly assigned to receiving an economic prompting question before or after being asked about their climate change views. The results show no effect of the prompting on belief in anthropogenic climate change, but they do show an effect of prompting on prioritization of taking urgent action to address climate change. Those with a non-positive view of the economy were less likely to support urgent action in comparison to those who considered the economy to be performing well if they were asked first about their economic evaluations. The salience of economic evaluations and the direction of such evaluations would not be significant if economic evaluations themselves were not important, and thus the findings also reveal that economic evaluations do matter.
\end{abstract}

\section{Key Policy Insights:}

- Belief in anthropogenic climate change is not affected by the salience of economic perceptions.

- Support for taking urgent action to implement policies to address climate change is impacted by the salience of macro-economic perceptions, with respondents who have their non-positive economic perceptions brought to the forefront of their minds displaying reduced support for urgent action.

- Policies that aim to tackle climate change are more likely to have bottom-up support from the public during periods when the economy is perceived to be prosperous.

Keywords: Britain; climate change; economic perceptions; survey experiments

\section{Acknowledgements:}

The author wishes to thank the team at YouGov for carrying out the data collection for this research. The author would also like to thank Stephen Fisher, the three anonymous reviewers and participants at the $3^{\text {rd }}$ Leuven-Montréal Winter School on Elections where an earlier draft of this paper was presented for helpful comments and suggestions.

Funding:

This work was supported by the Economic and Social Research Council [grant number ES/J500112/1] 


\section{The role of economic perceptions in influencing views on climate change: An experimental analysis with British respondents}

\section{Introduction:}

This paper investigates the role of perceptions of the state of the national economy in influencing individual views on climate change. The coincidence of a substantial increase in climate change scepticism across the western world with the 2008-2009 Great Recession has renewed interest in analysing the relationship between economic conditions and views on climate change (Kahn \& Kotchen, 2011; Scruggs \& Benegal, 2012). However, this shift in climate change views began prior to the recession and, while economic insecurity may have exacerbated this pre-existing trend (Nordhaus \& Shellenberger, 2009), isolating the role of economic perceptions from other explanatory factors - such as perceptions of weather changes (Krosnick, 2010), issue fatigue (Downs, 1972; Gough, 2011, p. 29), attention to the issue in the media (Boykoff \& Mansfield, 2008; Karlsson-Vinkhuyzen, Friberg, \& Saccenti, 2016; Leiserowitz, Maibach, Roser-Renouf, Smith, \& Dawson, 2013), and increasing partisan polarisation on the issue (Dunlap, McCright, \& Yarosh, 2016; McCright, Dunlap, \& Marquart-Pyatt, 2016) - remains to be satisfactorily achieved. Limitations of existing studies in making causal claims include the predominant reliance on repeated cross-sectional or pooled survey data and a focus on objective at the expense of subjective economic evaluations, thereby ignoring the heterogeneity in economic perceptions at any given time.

In this paper, the findings from an online randomly-assigned question-order survey experiment carried out on a representative sample of 1,751 British adults are presented. These findings address the question of whether economic perceptions affect respondents' views on climate change, specifically, belief in anthropogenic climate change and support for urgently addressing it. The study achieves this by focusing on the salience of economic perceptions, whereby salience is used to denote the prominence of economic perceptions in 
respondents' minds. After detailing the psychological mechanisms that may lead economic perceptions to affect climate change views, the next section discusses the difficulties in establishing a causal link between the two and expands upon the suitability of a questionorder experiment for tackling this question. The data is then presented and analysed before concluding by discussing the implications of the findings.

\section{Theoretical background:}

While the simultaneous occurrence of declines in economic fortunes and increases in climate change scepticism may suggest a connection between the two trends, what is it about feeling economically insecure that may trigger this? Cognitive dissonance theory provides one explanation. It proposes that individuals unconsciously seek consistency in their beliefs and mental frameworks and thus selectively interpret information. If information supports existing values and mental frameworks it will be readily accepted, but if it undermines beliefs it may be resisted, avoided or not perceived at all (Festinger, 1957). During periods of economic difficulties, people's value orientations may change, or at least fluctuate temporarily, as individuals prioritize their short-term material needs as their most immediate concern (Inglehart, 1983, 2008; Maslow, 1970). To reduce dissonance, individuals may downplay the threat that climate change poses or revaluate their beliefs about its existence (Scruggs \& Benegal, 2012) so they can justify to themselves their own actions that prioritize economic recovery over climate change mitigation.

Relatedly, system justification theory proposes that individuals have a psychological need to maintain a positive view of the existing social order which 'manifests itself, not surprisingly, in the strong tendency to perceive existing social relations as fair, legitimate and desirable, even in contexts in which those relations substantively disadvantage the person involved' (Nordhaus \& Shellenberger, 2009). As the economic and lifestyle changes that are advocated for tackling climate problems - and environmental problems generally - may contradict basic 
assumptions on the quality of life, economic prosperity and material needs (Kollmuss \& Agyeman, 2002, p. 255), system justification responses may be triggered whereby people are more willing to believe that the current system is working well rather than accept that there is a climate problem that may threaten life as they know it (Feygina, Jost, \& Goldsmith, 2010). And during times of economic instability, system justification responses may temporarily increase as individuals have a heightened motivation to defend a threatened system (Hennes, Ruisch, Feygina, Monteiro, \& Jost, 2016, p. 756).

It may also be that when prioritising action on climate change, individuals make a rational trade-off between what they perceive as two competing goals. Possessing only a finite capacity to worry, their concerns over climate change may be crowded out by economic anxiety during times of perceived economic difficulties. These explanations are facilitated by the fact that climate change is seen as a distant threat in time and space for many (Kollmuss \& Agyeman, 2002; Spence, Poortinga, \& Pidgeon, 2012) and so the issue may be relatively easier to deprioritize. During economic contractions, the media are also less likely to report on climate change as it focuses more on the economy and - with media coverage being a strong predictor of public concern for climate change - this may contribute towards individuals being less concerned about climate change during recessions (Carmichael \& Brulle, 2016).

Studies carried out in the aftermath of the Great Recession show - using repeated crosssectional or pooled survey data from the US - that increases in unemployment rates are significantly related to decreased levels of belief in global warming (Kahn \& Kotchen, 2011; Scruggs \& Benegal, 2012). Using US panel data from 2008 and 2011, Mildenberger and Leiserowitz (2017), however, find no effect on belief in global warming of changing objective state economic indicators or perceptions of the impact of the economic downturn on one's household. Other research finds that negative economic conditions have a 
correspondingly dampening effect on concern over climate change. For example, Kahn \& Kotchen (2011), Brulle, Carmichael \& Jenkins (2012) and Scruggs \& Benegal (2012) find that increases in unemployment rates are associated with decreased concern at the aggregate level, with Brulle, Carmichael and Jenkins (2012) additionally finding that increases in GDP have the opposite effect and Shum (2012) showing a positive relationship between economic growth rates and concern over climate change. Contrastingly, both Mildenberger \& Leiserowitz's (2017) and Krosnick \& MacInnis' (2012) analysis display no evidence that global warming attitudes are impacted by changing economic conditions, while Mayer \& Smith (2017) find that economic satisfaction does not significantly relate to one's willingness to pay higher taxes to combat climate change.

Rather than examining the impact of objective economic indicators, as has been the focus of much of the literature, this study examines the role of economic perceptions. Objective economic indicators can be problematic as they cannot take into account that, even in 'objectively' good or poor economic conditions, there will be heterogeneity in economic perceptions depending on the various individual factors that influence their formation. Such factors include partisanship - with individuals whose preferred party are in government having a tendency to perceive the state of the economy to be better (Evans \& Andersen, 2006) - and the use of cues from one's local area (Ansolabehere, Meredith, \& Snowberg, 2014; Reeves \& Gimpel, 2012), as well as perceptions being mediated by exposure to the media, personal experiences and various demographic characteristics (Duch, Palmer, \& Anderson, 2000). As individuals need to perceive economic conditions in order for them to impact upon their political attitudes, objective economic indicators may not capture their perceived reality. Thus 'subjective perceptions of economic conditions are the best indicators for examining how economic conditions relate to political attitudes' (Gabel \& Whitten, 1997, p. 84). 
However, as the factors that influence economic perceptions have been shown themselves to affect views on climate change, inferring whether economic perceptions influence climate change views independently of these is problematic. While most studies approach the issue using objective economic conditions - predominantly with repeated crosssectional or pooled data - the use of subjective economic measures is preferable for the reasons outlined above. Additionally, whether using objective or subjective economic measures, the reliance on repeated cross-sectional data is problematic for being able to address the risk of endogeneity. Notably, Kachi, Bernauer \& Gampfer (2015) attempted to address this through an online survey experiment in which they presented individuals with facts portraying the economy as either good or bad to see if economic perceptions impact upon climate policy support, but found no effects. This approach is limited though because, as the authors themselves note, individuals tend to have stable views of the state of the economy which may not be easily manipulated through an experimental information treatment. Thus, to overcome these issues and advance the state of the literature, an alternative approach is warranted.

This paper presents findings from an online randomly-assigned question-order experiment examining the impact of economic perceptions on climate change views. The experiment focuses on manipulating the salience of respondents' economic perceptions, whereby salience denotes the prominence in respondents' minds of their economic perceptions. Such question-order survey experiments have recently been used by Heath, Smith, Gilby \& Hoolahan (2015) to overcome a similar problem of endogeneity between subjective economic perceptions and partisanship. While experiments have been used in explaining various aspects of climate change attitudes ${ }^{1}$ they remain underutilized. Drews \&

\footnotetext{
${ }^{1}$ See Malka et al. 2009; Hardisty, Johnson, and Weber 2010; Parag, Capstick, and Poortinga 2011; Schuldt, 
Van Den Bergh (2016, p. 869) have advocated that 'future research may use more experiments to better identify the causal relation between factors and [climate] policy support'. In this experiment, respondents are randomly assigned to receiving a question on their economic perceptions either before or after being asked about their climate change views. There is a 'tendency for people to respond to questions at least partly on the basis of whatever ideas are imminently salient to them' (Zaller, 1992, p. 79) and so being asked the economic question should prime individuals to bring their economic perceptions to the forefront of their minds. The salience of economic perceptions is expected to affect climate change views as per the reasons discussed, but there is no reason to believe that the salience of climate change to the respondent should alter economic perceptions thus the questionorder effects should be partially non-separable (Lacy, 2001). As people may perceive a tradeoff between economic prosperity and protecting the climate which may lead to conflicting views, this makes such an experiment an ideal and appropriate method (Tourangeau, Rasinski, Bradburn, \& D’Andrade, 1989).

Given the sample size, there is not enough statistical power to test these effects within the economic evaluation response categories; instead the tests will concentrate on identifying overall interaction effects where statistical power will be greater. The following are the hypotheses that will be tested:

H1: The effect of prompting on belief in anthropogenic climate change will be different according to one's economic evaluations, with those who think the economy is doing well on average having higher levels of belief than those who do not upon prompting.

$\mathrm{H} 2$ : The effect of prompting on prioritization of action on climate change will be different according to one's economic evaluations, with those who think the 
economy is doing well on average having higher support for prioritization than those who do not upon prompting.

Bringing positive economic perceptions to the forefront of respondents' minds is expected to result in higher reported levels of belief in the anthrophonic cause of climate change and support for taking urgent action to address it and vice versa for those who have their gloomy economic perceptions primed, and it is the difference between these that this study is interested in. While actual economic realities cannot be manipulated, if economic realities affect climate change views it ought to depend on the salience of such realities to the respondent. Thus, this experiment does not seek to move the needle on individuals' assessment of the economy - which may be difficult to achieve - but instead manipulates the salience of their economic perceptions. It should also be noted that though different theoretical mechanisms are proposed for why economic perceptions may adversely affect climate views, this current research is not designed to test which mechanisms provide the most appropriate explanation but rather to test what ought to happen to climate change views if people are affected by the salience of their economic orientations. While both $\mathrm{H} 1$ and $\mathrm{H} 2$ test a relationship between climate change views and the salience of economic perceptions, they each have a distinct focus. It is more onerous for the salience of economic perceptions to affect belief in, than prioritization of, climate change. Given this and the subtleness of the prompting, it is optimistic to expect $\mathrm{H} 1$ to be confirmed but as previous studies have identified a link between economic conditions and climate beliefs (Kahn \& Kotchen, 2011; Scruggs \& Benegal, 2012) it will be tested.

\section{Data:}

An online randomly-assigned question-order experiment was carried out on 9-10 December 2015 in conjunction with YouGov on a sample of 1,751 British adults from their online 
panel, weighted to be representative of the British adult population ${ }^{2}$. Respondents were asked, 'In your opinion, how good or bad is the state of Britain's economy at the moment?'. The treatment group were first primed with this question followed by questions about their belief in anthropogenic climate change and how urgent an issue they perceived addressing it to $\mathrm{be}^{3}$. The control group was asked the same questions but had the climate change questions placed before the economic perception question. Responses to the economic perception question were almost identical among the treatment and control groups, supporting the expectation that economic perceptions should not be affected by climate change views. These responses are displayed in Table 1.

\section{[INSERT TABLE 1 HERE]}

These questions have previously been fielded by YouGov and have proved reliable measures of public opinion on climate change. Their repeated use furthers the consistent tracking of climate change views. In addition to capturing authentic rather than contrived economic perceptions, the subtleness of the prompt increases the chances of respondents being consciously unaware of it. This is the ideal scenario as otherwise respondents can decide whether they will go along with the prompt or supress it (Kubovy, 1977; Schwarz \& Clore, 1983; Strack, 1992). Furthermore, the 'harm our standard of living' wording in the second response to the second question aids the association with the economic perception questions. This economic priming also mimics actual framing on the issue to which people may be exposed and, akin to the question-order effects that are being tested, such framing is

\footnotetext{
${ }^{2}$ YouGov is an online polling company that utilises active sampling and weights their data by age, gender, social class, region, level of education, vote at the previous election and political interest with their target data derived from four sources. Further information on their methodology can be found on their website (YouGov, 2017).

${ }^{3}$ See appendix for exact wording.
} 
often only effective if it resonates with its targets' pre-existing interpretations (Nisbet, 2009, p. 17).

To begin with, it is necessary to assess whether the randomisation process balanced individual characteristics across the treatment groups (Angrist \& Pischke, 2009, p. 18). Chisquare tests of independence were carried out on a range of characteristics to assess $\operatorname{this}^{4}$. In all cases, no significant relationship was found $(\mathrm{p} \leq 0.05)$. A borderline imbalance of gender at the $\mathrm{p}=.06$ level was however noted ${ }^{5}$. As females have been shown to express greater concern about climate change than males (McCright, 2010), the results have been checked carefully to verify whether this may have an impact upon them and the outcomes are outlined below. Crucially for verifying that climate change views do not affect economic evaluations, there is no significant difference in the distribution of economic evaluations across treatment and control groups.

Furthermore, tests were carried out restricting the samples to those within each of the economic evaluation categories. The only case of concern arises with an imbalance of Green Party voters among those with 'very bad' economic evaluations ${ }^{6}$. This is problematic given

\footnotetext{
${ }^{4}$ Age, class, education, ethnicity, gender, gross household income, industry, newspaper readership, region, urban/rural area, vote at previous general election and work status.

${ }^{5}$ While the control group has a gender balance, the treatment group is made up of 46.5 per cent males (402 cases) and 53.5 per cent females (462 cases). Further investigating this by carrying out tests within each of the economic evaluation categories, there are no imbalance issues between treatment and gender conditional on having good economic evaluations. While not approaching the $\mathrm{p} \leq 0.05$ level, it is within the categories of quite negative and neither good nor bad economic evaluations conditional on treatment where there is a potential imbalance issue just outside this significance level.

${ }^{6}$ While within every other economic evaluation response Green Party voters are balanced between the treatment and control groups, within the very negative economic evaluation response they are absent from the control yet make up 13 per cent (seven cases) of the treatment group.
} 
the relationship between partisanship and climate change attitudes (Linde, 2017), especially given that Green Party supporters tend to be strongly supportive of environmental protection measures and critical of the Conservative's handling of the economy (Dennison, 2017). Regardless of this identified imbalance, the small number of respondents who consider the economy to be very bad (6 per cent) behave oddly in subsequent tests and display outlying patterns which questions whether valid inferences can be made from this particular group. Thus, those with very bad economic evaluations have been excluded from further analyses.

\section{Analysis:}

To give a preliminary indication of patterns within the data, crosstabulations are presented displaying the aggregate responses to the climate change questions by economic evaluation for the control group, and how the aggregate responses for the treatment group differ from these. Table 2 displays responses to the question about belief in anthropogenic climate change. Looking at the percentage figures on the left-hand side, it initially shows that those with quite bad economic evaluations have a higher proportion of respondents than the other economic evaluation categories who believe in anthropogenic climate change. Rather than being counter-intuitive, this should be expected in the aggregate responses due to the role of partisanship. Conservative Party supporters tend to view the economy more favourably with their party being in government while traditionally being more climatesceptic and Labour Party supporters tend to view the economy less favourably with their party being in opposition while traditionally being more sympathetic to climate change issues (Carter \& Clements, 2015, p. 206; 218).

It is the difference between the treatment and control groups that should reveal an isolated effect of the salience of economic perceptions, but the figures display little evidence of any. While receiving the prompt among those with good economic perceptions is 
associated with higher levels and among those with quite bad economic perceptions is associated with lower levels of belief in anthropogenic climate change and thus is in the hypothesised direction, the magnitude is quite low at three and one percentage points respectively. The observed differences in the neither good nor bad category between treatment and control groups can be attributed to a gender imbalance within this economic response category where males show no noticeable differences, yet females - who are more concerned about the climate - are overrepresented in the treatment group. Thus, the initial results from the descriptive statistics does not suggest a large effect, if any at all.

\section{[INSERT TABLE 2 HERE]}

Table 3 displays crosstabulations between one's perceived urgency of addressing climate change and respondents' economic perceptions by control and treatment groups ${ }^{7}$. Focusing on the difference between the responses of the control and treatment groups, the crosstabulations provide support for an effect of priming on one's perceived sense of urgency to address climate change. Those with good economic evaluations have higher proportions of respondents that would prioritize urgent action if they have been primed with their economic evaluations first. Similarly, those with neither good nor bad or quite bad economic evaluations have lower proportions of respondents that would prioritize urgent action if they receive the economic prompt. Looking at the magnitude of the difference in the percentage point change in the treatment minus control columns between prioritising action and believing that one should not rush into action, one sees a widening gap between these responses of ten, fifteen and seven percentage points respectively for having good, neither

\footnotetext{
${ }^{7}$ Due to an author error, the survey was administered with the climate sceptic and climate denier responses pooled as one response category. However, from the previous question, it was possible to separate out these post-survey. As the experiment examines the difference between those who would and would not prioritize urgent action, for which this error should not result in cross-contamination, this should not affect the results.
} 
and bad economic evaluations. Unlike for belief in climate change, among the neither good nor bad and quite bad economic categories - where there was a borderline gender imbalance there are no noticeable difference in how males and females responded to the treatment. There is also little difference between the control and the treatment group for those that do not believe in climate change.

\section{[INSERT TABLE 3 HERE]}

To test whether these differences are statistically significant, logistic regressions are carried out in which the dependent variables are dichotomized ${ }^{8}$ and regressed on receiving the treatment, one's economic evaluations and the interaction between both of these as well as some controls 9 . Results for the belief in anthropogenic climate change question are displayed in table 4. Regardless of whether control covariates are included or not, the results indicate no significance for the interaction term of interest. This remains the case whether the neither good nor bad economic evaluations category is used as the reference category as displayed or good/quite bad economic evaluations are alternatively used. Thus, H1 is rejected.

\section{[INSERT TABLE 4 HERE]}

The results for the urgency of addressing climate change question are displayed in table 5. The models on the left-hand side are carried out on the full sample ${ }^{10}$ and in models on

\footnotetext{
${ }^{8}$ For belief in climate change, the dependent variable is coded as 1 if one believes in anthropogenic climate change and 0 if one does not state this. For urgency of addressing climate change, the dependent variable is coded 1 if one believes that urgent action is needed and 0 if one does not believe this.

${ }^{9}$ Education, partisanship, gender and region.

${ }^{10}$ Less those who responded 'don't know' and 'very bad' to the economic evaluation question for reasons discussed above.
} 
the right-hand those who do not believe in anthropogenic climate change, and are thus unlikely to prioritize action on climate change regardless (Krosnick, Holbrook, Lowe, \& Visser, 2006), are removed. Models are additionally displayed showing the results under each of these samples when covariates are and are not included. Firstly, in all models, the negative association between economic evaluations on their own and the dependent variable - which is statistically significant between the good and quite bad categories - is as expected given the role that partisanship plays in the formation of economic perceptions and how partisanship also impacts upon climate change views as discussed previously ${ }^{11}$.

It is the interaction term between economic evaluations and receiving the treatment of prior economic prompting that allows such an issue to be overcome. Compared to the baseline group, respondents who receive the treatment and have good economic evaluations are statistically more likely at the $\mathrm{p} \leq 0.05$ level to support urgent action to tackle climate change in all models. An indication of the magnitude of these effects can be seen by calculating predicted probabilities for all possible combinations of economic evaluations and being in the treatment/control group, with everything else in the models kept at their mean value. In model 2 - the full sample model that includes covariates - there is an eight percentage point difference between the predicted probabilities of supporting action among those who have good economic evaluations if they have received the treatment (47 per cent) versus if they have not (39 per cent), an eight percentage point difference among those with neither good nor bad economic evaluations if they have received the treatment (39 per cent) versus if they have not (47 per cent) and a four percentage point difference among those with quite bad economic evaluations if they have received the treatment (50 per cent) versus if they have not (54 per cent), in all cases in the hypothesized directions. When non-believers in

\footnotetext{
${ }^{11}$ Carrying out logistic regression analysis without the interaction term confirms that this negative relationship disappears when partisanship is accounted for.
} 
anthropogenic climate change are removed from the sample, this increases the magnitude of the effect. Predicted probabilities show that treatment in model 4 has a most substantial effect among those with neither good nor bad economic evaluations where there is a fifteen per cent difference between those who received the treatment (59 per cent) and those who did not (74 per cent). Thus, $\mathrm{H} 2$ is accepted ${ }^{12}$.

\section{[INSERT TABLE 5 HERE]}

It is also worth examining how the magnitude of this effect compares with the magnitude of the effects of other predictors in the model. When predicted probabilities are calculated separately for the other covariates in the model and holding everything else at their mean value, this eight percentage point effect for model 2 compares quite favourably to the magnitude of the effect of region, where there is an eleven percentage point difference between those from London (51 per cent) and those from the North (40 per cent) - and to education where there is a thirteen percentage point difference in the predicted probability of going from no formal education (38 per cent) to holding a masters or $\mathrm{PhD}$ qualification (51 per cent). All of these are still dwarfed by partisanship where Liberal Democrat voters, as the most supportive of action in the model, have a 64 per cent probability of prioritising climate change action whereas for Conservatives voters this is only 36 per cent ${ }^{13}$.

\footnotetext{
${ }^{12}$ For robustness, multinomial regressions were carried out for models $1 \& 2$ in which the category for not prioritising urgent action on climate change was broken down into those who believe in the occurrence of climate change but do not want to rush into action, those who are either unsure or do not believe in climate change and the 'don't know' category (table contained in supplementary online appendix). Relative to the base outcome of those who prioritise urgent action, the interaction terms indicate that those who received the treatment and have good rather than neither good nor bad economic evaluations are less likely to respond with each of these 'non-prioritisation' responses. While only statistically significant for the category of those who do not want to rush into action, this is likely a power issue due to the small sample size in the other two categories.

${ }^{13}$ Predicted probabilities were not calculated for gender as it was not statistically significant.
} 


\section{Conclusions:}

This research aimed to examine whether the salience of economic perceptions independently affects belief in anthropogenic climate change and support for taking action to address it. This was investigated through the use of an online question-order experiment which allows for the effect to be isolated from other contributing causes.

No association was found between the salience of economic perceptions and belief in anthropogenic climate change. While contrary to the findings of studies investigating the broader link between economic conditions and climate beliefs that have used repeated crosssectional or pooled data, it is in line with the results of Mildenberger \& Leiserowitz (2017) who reached similar conclusions using panel data analysis. As both the panel-data analysis that they used and the experimental method used in this paper are better equipped to unearth causal mechanisms, this further suggests that there is no direct causal link between economic conditions and belief in anthropogenic climate change.

A statistically significant relationship was, however, found between the salience of economic perceptions and support for urgently tackling climate change. Namely, those who received the economic question first and had good economic evaluations were more likely to support urgent action while the reverse was true for those with neither good nor bad or quite bad economic evaluations. The results suggest that the effects of economic uncertainty on support for action on climate change is particularly strong. An effect of the salience and direction of economic evaluations on support for action would not occur if economic evaluations themselves were not important, and thus the findings suggest that economic evaluations do matter. While this further strengthens results from cross-sectional data analysis, it runs counter to the findings from the experimental analysis of Kachi, Bernauer \& Gampfer (2015) as well as the panel-data analysis of Mildenberger \& Leiserowitz. On the former, as mentioned, their manipulation may not have worked as they tried to prime people with 
economic facts while individuals' economic perceptions at any given point may be relatively stable. As the design of this current experiment used respondents' own economic perceptions, then such an issue was overcome. On the latter, the authors were looking at the effect of subjective evaluations of the recession on one's household rather than the effect of subjective evaluations of the economy itself. Thus, it may be that sociocentric rather than the egocentric perceptions of economic hardship matter more for the prioritisation of action on climate change. Given that Mayer \& Smith (2017, p. 354) find that some but not all types of subjective economic assessments matter for being willing to pay for climate policy, future studies should pay more attention to the measure of subjective economic evaluations being used.

It is worth noting that the experiment took place during a period of unusually high salience for climate change, coinciding with the 2015 Paris Climate Conference. The fact that a subtle prompt affects views on climate change prioritization during a high profile climate change conference - and thus a rare occasion when climate policy is placed in the public spotlight and is a tangible and immediate public policy issue - indicates that the public are affected by the salience of economic perceptions when deciding whether to prioritize mitigation measures. Future research may examine whether the extent of this relationship would be of a similar magnitude during periods of lower climate change salience. Additionally, to test how long such effects last, the inclusion of attitudinal climate change and economic perception questions concurrently in longitudinal panel data is necessary. And while one would expect the effect of the salience of economic perceptions on climate change beliefs and attitudes to behave similarly in other developed countries, future research should also test this through similar research in other national contexts.

Overall, the findings highlight that a portion of the public continue to link protecting the climate with economic sacrifices. As a result, they are cautious about undertaking remedial 
action on climate change during uncertain economic periods. This presents challenges when the economy is not - or at least not perceived to be - performing well. It also highlights how an emphasis on economic woes prior to discussions on climate change in public discourse may reduce support for climate change mitigation. Finding ways to lessen this link - such as by focusing on the economic benefits that can come with climate change mitigation measures through the conversion to a green economy - will be vital if public support for tackling climate change is to last during challenging economic times.

\section{References:}

Angrist, J. D., \& Pischke, J.-S. (2009). Mostly Harmless Econometrics: An Empiricist's Companion. Princeton: Princeton University Press.

Ansolabehere, S., Meredith, M., \& Snowberg, E. (2014). Mecro-Economic Voting: Local Information and Micro-Perceptions of the Macro-Economy. Economics \& Politics, 26(3), 380-410.

Bolsen, T., Leeper, T. J., \& Shapiro, M. A. (2014). Doing What Others Do: Norms, Science, and Collective Action on Global Warming. American Politics Research, 42(1), 65-89.

Boykoff, M. T., \& Mansfield, M. (2008). "Ye Olde Hot Aire”: Reporting on human contributions to climate change in the UK tabloid press. Environmental Research Letters, 3(2), 1-8.

Brulle, R. J., Carmichael, J., \& Jenkins, J. C. (2012). Shifting public opinion on climate change: an empirical assessment of factors influencing concern over climate change in the U.S., 2002-2010. Climatic Change, 114(2), 169-188.

Carmichael, J. T., \& Brulle, R. J. (2016). Elite cues, media coverage, and public concern: an integrated path analysis of public opinion on climate change, 2001-2013. Environmental Politics, 26(2), 232-252.

Carter, N., \& Clements, B. (2015). From “Greenest Government Ever" to "Get Rid of the 
Green Crap": David Cameron, the Conservatives and the Environment. British Politics, 10(2), 204-225.

Dennison, J. (2017). The Greens in British Politics: Protest, Anti-Austerity and the Divided Left. London: Palgrave Macmillan.

Downs, A. (1972). Up and down with ecology: The "Issue-Attention cycle." The Politics of American Economic Policy Making, 28, 38-50.

Drews, S., \& van den Bergh, J. C. J. M. (2016). What explains public support for climate policies? A review of empirical and experimental studies. Climate Policy, 16(7), 855876.

Duch, R. M., Palmer, H. D., \& Anderson, C. J. (2000). Heterogeneity in Perceptions of National Economic Conditions. American Journal of Political Science, 44(4), 635-652.

Dunlap, R. E., McCright, A. M., \& Yarosh, J. H. (2016). The Political Divide on Climate Change: Partisan Polarization Widens in the U.S. Environment: Science and Policy for Sustainable Development, 58(5), 4-23.

Evans, G., \& Andersen, R. (2006). The Political Conditioning of Economic Perceptions. The Journal of Politics, 68(1), 194-207.

Festinger, L. (1957). A theory of cognitive dissonance. Evanston, Illinois: Row, Peterson and Company.

Feygina, I., Jost, J. T., \& Goldsmith, R. E. (2010). System Justification, the Denial of Global Warming, and the Possibility of \&quot; System- Sanctioned Change \&quot; Article Personality and Social Psychology Bulletin, 36(3), 326-338.

Gabel, M., \& Whitten, G. D. (1997). Economic Conditions, Economic Perceptions, and Public Support for European Integration. Political Behavior, 19(1), 81-96.

Gough, I. (2011). Climate Change and Public Policy Futures. London: British Academy. Hardisty, D. J., Johnson, E. J., \& Weber, E. U. (2010). A dirty word or a dirty world?: 
Attribute framing, political affiliation, and query theory. Psychological Science, 21(1), 86-92.

Heath, O., Smith, P., Gilby, N., \& Hoolahan, F. (2015). Partisan Priming and Subjective Evaluations of the Economy: Evidence from a Survey Experiment. Journal of Elections, Public Opinion and Parties, 25(4), 530-542.

Hennes, E. P., Ruisch, B. C., Feygina, I., Monteiro, C. A., \& Jost, J. T. (2016). Motivated recall in the service of the economic system: The case of anthropogenic climate change. Journal of Experimental Psychology: General, 145(6), 755-771.

Inglehart, R. (1983). The Persistence of Materialist and Post-Materialist Value Orientations: Comments on Van Deth's Analysis. European Journal of Political Research, 11(1), 8191.

Inglehart, R. (2008). Changing Values among Western Publics from 1970 to 2006. West European Politics, 31(1-2), 130-146.

Kachi, A., Bernauer, T., \& Gampfer, R. (2015). Climate policy in hard times: Are the pessimists right? Ecological Economics, 114, 227-241.

Kahn, M. E., \& Kotchen, M. J. (2011). Business Cycle Effects on Concern About Climate Change: the Chilling Effect of Recession. Climate Change Economics, 2(3), 257-273.

Karlsson-Vinkhuyzen, S. I., Friberg, L., \& Saccenti, E. (2016). Read all about it!? Public accountability, fragmented global climate governance and the media. Climate Policy, 17(8), 982-987.

Kollmuss, A., \& Agyeman, J. (2002). Mind the Gap: Why Do People Behave Environmentally and What are the Barriers to Pro-Environmental Behaviour. Environmental Education Research, 8(3), 239-260.

Krosnick, J. A. (2010). The Climate Majority. The New York Times.

Krosnick, J. A., Holbrook, A. L., Lowe, L., \& Visser, P. S. (2006). The Origins and 
Consequences of democratic citizens' Policy Agendas: A Study of Popular Concern about Global Warming. Climatic Change, 77(1), 7-43.

Krosnick, J. A., \& MacInnis, B. (2012). Trends in American Public Opinion on Global Warming Policies Between 2010 and 2012.

Kubovy, M. (1977). Response availability and the apparent spontaneity of numerical choices. Journal of Experimental Psychology: Human Perception and Performance, 3(2), 359364.

Lacy, D. (2001). A Theory of Nonseparable Preferences in Survey Responses. American Journal of Political Science, 45(2), 239-258.

Leiserowitz, A., Maibach, E., Roser-Renouf, C., Smith, N., \& Dawson, E. (2013). Climategate, Public Opinion, and the Loss of Trust. American Behavioral Scientist, 57(6), 818-837.

Linde, S. (2017). Political communication and public support for climate mitigation policies: a country-comparative perspective. Climate Policy. https://doi.org/10.1080/14693062.2017.1327840

Malka, A., Krosnick, J. A., Debell, M., Pasek, J., \& Schneider, D. (2009). Featuring Skeptics in News Media Stories About Global Warming Reduces Public Beliefs in the Seriousness of Global Warming. Retrieved April 9, 2014, from http://climatepublicopinion.stanford.edu/wp-content/uploads/2013/04/Global-WarmingSkeptics-Summary.pdf

Maslow, A. H. (1970). Motivation and Personality (2nd ed.). New York: Harper and Row. Mayer, A., \& Smith, E. K. (2017). Rethinking Economic Conditions and Environmental Attitudes: Macroeconomic Effects, Individual Experiences, and Subjectivity. Social Currents, 4(4), 342-359.

McCright, A. M. (2010). The effects of gender on climate change knowledge and concern in 
the American public. Population and Environment, 32(1), 66-87.

McCright, A. M., Dunlap, R. E., \& Marquart-Pyatt, S. T. (2016). Political ideology and views about climate change in the European Union. Environmental Politics, 25(2), 338-358.

Mildenberger, M., \& Leiserowitz, A. (2017). Public Opinion on Climate Change: Is there an Economy-Environment Tradeoff? Environmental Politics, 26(5), 801-824.

Nisbet, M. C. (2009). Communicating Climate Change: Why Frames Matter for Public Engagement. Environment: Science and Policy for Sustainable Development, 51(2), 12 23.

Nordhaus, T., \& Shellenberger, M. (2009). Apocalypse Fatigue: Losing the Public on Climate Change. Retrieved March 20, 2014, from www.e360.yale.edu/feature/apocalypse_fatigue_losing_the_public_on_climate_change/ $2210 /$

Parag, Y., Capstick, S., \& Poortinga, W. (2011). Policy attribute framing: A comparison between three policy instruments for personal emissions reduction. Journal of Policy Analysis and Management, 30(4), 889-905.

Reeves, A., \& Gimpel, J. G. (2012). Ecologies of Unease: Geographic Context and National Economic Evaluations. Political Behavior, 34(3), 507-534.

Schuldt, J. P., Konrath, S. H., \& Schwarz, N. (2011). "Global warming” or "Climate change"?: Whether the planet is warming depends on question wording. Public Opinion Quarterly, 75(1), 115-124.

Schwarz, N., \& Clore, G. L. (1983). Mood, misattribution, and judgments of well-being: Informative and directive functions of affective states. Journal of Personality and Social Psychology, 45(3), 513-523.

Scruggs, L., \& Benegal, S. (2012). Declining Public Concern about Climate Change: Can we Blame the Great Recession? Global Environmental Change, 22(2), 505-515. 
Shum, R. Y. (2012). Effects of Economic Recession and Local Weather on Climate Change Attitudes. Climate Policy, 12(1), 38-49.

Spence, A., Poortinga, W., \& Pidgeon, N. (2012). The Psychological Distance of Climate Change. Risk Analysis, 32(6), 957-972.

Strack, F. (1992). "Order Effects" in Survey Research: Activation and Information Functions of Preceding Questions. In N. Schwarz \& S. Sudman (Eds.), Context Effects in Social and Psycological Research (pp. 23-34). New York: Springer-Verlag.

Tourangeau, R., Rasinski, K. A., Bradburn, N., \& D’Andrade, R. (1989). Carryover Effects in Attitude Surveys. Public Opinion Quarterly, 53(4), 495-524.

YouGov. (2017). Panel Methodology. Retrieved September 18, 2017, from https://yougov.co.uk/about/panel-methodology/

Zaller, J. (1992). The Nature and Origins of Mass Public Opinion. Cambridge: Cambridge University Press. 


\section{Tables:}

Table 1: Economic Evaluations by Control and Treatment

\begin{tabular}{lcccc}
\hline \hline & \multicolumn{2}{c}{ Control } & \multicolumn{2}{c}{ Treatment } \\
\hline Economic Evaluation & $\%$ & $\mathrm{~N}$ & $\%$ & $\mathrm{~N}$ \\
Very Good & 1.5 & 12 & 1.5 & 232 \\
Quite Good & 28 & 253 & 27.5 & 294 \\
Neither Good Nor Bad & 34 & 311 & 35 & 219 \\
Quite Bad & 26 & 238 & 26 & 51 \\
Very Bad & 6.5 & 58 & 6 & 31 \\
Don't Know & 4 & 37 & 3.5 & 842 \\
N & 100 & 909 & 99.5 & \\
\hline \hline
\end{tabular}

Note: Due to rounding from weights, the total $\mathrm{N}$ in the Treatment group does not exactly match the addition of its components

Table 2. Crosstabulation of Climate Change Beliefs with Economic Evaluations by Treatment (\%).

\begin{tabular}{|c|c|c|c|c|c|c|c|}
\hline & \multicolumn{3}{|c|}{ Control(C) } & \multirow{2}{*}{\multicolumn{3}{|c|}{ Treatment (T)-Control }} & \multirow[t]{3}{*}{$\mathrm{n}(\mathrm{C}+\mathrm{T}$} \\
\hline & \multicolumn{3}{|c|}{ Economic Evaluations } & & & & \\
\hline & Good & Neither & $\begin{array}{l}\text { Quite } \\
\text { Bad }\end{array}$ & Good & Neither & $\begin{array}{l}\text { Quite } \\
\text { Bad }\end{array}$ & \\
\hline Climate Change Belief: & & & & & & & \\
\hline $\begin{array}{l}\text { Changing as a result of human } \\
\text { activity }\end{array}$ & 57 & 58 & 71 & +3 & +6 & -1 & 1089 \\
\hline $\begin{array}{l}\text { Changing but not because of } \\
\text { human activity }\end{array}$ & 27 & 23 & 14 & 0 & -6 & 0 & 358 \\
\hline Not Changing & 4 & 3 & 5 & -1 & 0 & -3 & 61 \\
\hline Not Sure & 13 & 15 & 10 & -2 & -1 & +4 & 243 \\
\hline Sum & 101 & 99 & 100 & & & & 1751 \\
\hline
\end{tabular}

Note: 'Very Bad' (n=109) and 'Don't Know' (n=69) responses to the economic evaluation question are not displayed 
Table 3. Crosstabulation of Climate Change Action with Economic Evaluations by Treatment (\%).

\begin{tabular}{|c|c|c|c|c|c|c|c|}
\hline & \multicolumn{3}{|c|}{ Control $(\mathrm{C})$} & \multicolumn{3}{|c|}{ Treatment(T)-Control } & \multirow[t]{3}{*}{$\mathrm{n}(\mathrm{C}+\mathrm{T})$} \\
\hline & \multicolumn{3}{|c|}{ Economic Evaluations } & \multicolumn{3}{|c|}{ Economic Evaluations } & \\
\hline & Good & Neither & $\begin{array}{c}\text { Quite } \\
\text { Bad }\end{array}$ & Good & Neither & $\begin{array}{c}\text { Quite } \\
\text { Bad }\end{array}$ & \\
\hline Climate Change Views: & & & & & & & \\
\hline $\begin{array}{l}\text { Happening and requires urgent } \\
\text { action }\end{array}$ & 36 & 47 & 56 & +7 & -6 & -3 & 796 \\
\hline $\begin{array}{l}\text { Happening and does not require } \\
\text { urgent action }\end{array}$ & 39 & 29 & 22 & -3 & +9 & +4 & 534 \\
\hline Unclear if it is occurring & 15 & 12 & 10 & -3 & -5 & -2 & 179 \\
\hline Not happening & 4 & 3 & 4 & -1 & 0 & -1 & 52 \\
\hline Don’t know & 7 & 9 & 8 & 0 & +3 & 0 & 190 \\
\hline Sum & 101 & 100 & 100 & & & & 1,751 \\
\hline
\end{tabular}

Note: 'Very Bad' ( $\mathrm{n}=109)$ and 'Don't Know' $(\mathrm{n}=69)$ responses to the economic evaluation question are not displayed 
Table 4. Logistic Regression of Treatment and Economic Evaluations on Belief in Anthropogenic Climate Change.

\begin{tabular}{lll}
\hline \hline & $\begin{array}{l}\text { Model 1-Without } \\
\text { covariates }\end{array}$ & $\begin{array}{l}\text { Model 2-With } \\
\text { covariates }\end{array}$ \\
Treated & 0.265 & 0.189 \\
& $(0.187)$ & \\
Neither Good nor Bad Economic Evaluations & & $0.197)$ \\
Quite Bad & $0.554 * *$ & $(0.216)$ \\
& $(0.204)$ & 0.097 \\
Good & -0.058 & $(0.205)$ \\
& $(0.191)$ & \\
Treatment*Neither Good nor Bad Economic Evaluations & & -0.298 \\
Treated*Quite Bad & -0.308 & $(0.307)$ \\
& $(0.293)$ & -0.009 \\
Treated*Good & & $(0.289)$ \\
& -0.138 & -0.855 \\
Constant & $(0.276)$ & $(0.335)$ \\
ll(null) & & -1038.261 \\
Observations & 0.324 & -951.890 \\
\hline \hline
\end{tabular}

Note: Those who responded 'don't know' to the economic evaluation question have been excluded, as have those that responded 'very bad' for reasons discussed above. Education, partisanship, gender and region are also included as controls in model 2 , but their coefficients are not displayed.

$* \mathrm{p} \leq 0.05 ; * * \mathrm{p} \leq 0.01$; Coefficients are log-odds ratios; Standard Errors in parentheses 
Table 5. Logistic Regression of Treatment and Economic Evaluations on Urgency of Addressing Climate Change.

\begin{tabular}{|c|c|c|c|c|}
\hline & \multicolumn{2}{|c|}{ Full Sample } & \multicolumn{2}{|c|}{$\begin{array}{l}\text { Among Anthropogenic } \\
\text { Climate Change Believers }\end{array}$} \\
\hline & $\begin{array}{l}\text { Model } 1- \\
\text { Without } \\
\text { covariates }\end{array}$ & $\begin{array}{l}\text { Model } 2- \\
\text { With } \\
\text { covariates }\end{array}$ & $\begin{array}{l}\text { Model 3- } \\
\text { Without } \\
\text { covariates }\end{array}$ & $\begin{array}{l}\text { Model 4- } \\
\text { With } \\
\text { covariates }\end{array}$ \\
\hline Treated & $\begin{array}{l}-0.264 \\
(0.183)\end{array}$ & $\begin{array}{l}-0.346 \\
(0.191)\end{array}$ & $\begin{array}{l}-0.585^{*} \\
(0.247)\end{array}$ & $\begin{array}{l}-0.606^{*} \\
(0.257)\end{array}$ \\
\hline \multicolumn{5}{|c|}{$\begin{array}{l}\text { Neither Good nor Bad Economic } \\
\text { Evaluations }\end{array}$} \\
\hline Quite Bad & $\begin{array}{l}0.378 * \\
(0.192)\end{array}$ & $\begin{array}{l}0.265 \\
(0.201)\end{array}$ & $\begin{array}{l}0.067 \\
(0.266)\end{array}$ & $\begin{array}{l}0.100 \\
(0.269)\end{array}$ \\
\hline Good & $\begin{array}{l}-0.436^{*} \\
(0.194)\end{array}$ & $\begin{array}{l}-0.324 \\
(0.202)\end{array}$ & $\begin{array}{l}-0.548 * \\
(0.261)\end{array}$ & $\begin{array}{l}-0.495 \\
(0.268)\end{array}$ \\
\hline \multicolumn{5}{|c|}{$\begin{array}{l}\text { Treatment*Neither Good nor Bad } \\
\text { Economic Evaluations }\end{array}$} \\
\hline Treated*Quite Bad & $\begin{array}{l}0.139 \\
(0.277)\end{array}$ & $\begin{array}{l}0.176 \\
(0.292)\end{array}$ & $\begin{array}{l}0.462 \\
0.381)\end{array}$ & $\begin{array}{l}0.458 \\
(0.393)\end{array}$ \\
\hline Treated*Good & $\begin{array}{l}0.543^{*} \\
(0.275)\end{array}$ & $\begin{array}{l}0.650^{*} \\
(0.280)\end{array}$ & $\begin{array}{l}0.914^{*} \\
(0.365)\end{array}$ & $\begin{array}{l}0.981 * * \\
(0.370)\end{array}$ \\
\hline Constant & $\begin{array}{l}-0.121 \\
(0.129)\end{array}$ & $\begin{array}{l}-0.661 \\
(0.326)\end{array}$ & $\begin{array}{l}1.003 * * \\
(0.183)\end{array}$ & $\begin{array}{l}1.135^{*} \\
(0.485)\end{array}$ \\
\hline 11(null) & -1084.540 & -1084.540 & -617.822 & -617.822 \\
\hline $11($ model $)$ & -1069.993 & -1017.485 & -610.392 & -594.587 \\
\hline Observations & 1573 & 1573 & 997 & 997 \\
\hline
\end{tabular}

Note: Those who responded 'don't know' to the economic evaluation question have been excluded, as have those that responded 'very bad' for reasons discussed above. Education, partisanship, gender and region are also included as controls in these regressions in models 2 and 4, but their coefficients are not displayed.

$* \mathrm{p} \leq 0.05 ; * * \mathrm{p} \leq 0.01$; Coefficients are log-odds ratios; Standard Errors in parentheses 


\section{Appendix: Question Wording}

In your opinion, how good or bad is the state of Britain's economy at the moment?

- Very good

- Quite good

- Neither good nor bad

- Quite bad

- Very bad

- Don't Know

On the subject of climate change do you think:

- The world's climate is changing as a result of human activity

- The world's climate is changing but NOT because of human activity

- The world's climate is NOT changing

- Not sure

Thinking about global warming and climate change, which of these statements comes closest to your view:

- It is a serious and urgent problem and radical steps must be taken NOW to prevent terrible damage being done to the planet.

- Climate change is definitely happening but there is time to work out the best actions to take, and we should not rush into anything that could harm our standard of living.

- It is not yet clear whether climate change is happening or not - scientists are divided on this issue.

- I don't believe climate change is happening at all - it's simply scare-mongering and we should ignore $i^{14}$.

- Don't Know

\footnotetext{
${ }^{14}$ As discussed in footnote 8 , the climate sceptic and denier responses were mistakenly fielded in the same response category. Using responses to the climate belief question, it was possible to separate out climate deniers from climate sceptics post-survey
} 